\title{
Implementasi Kebijakan Pakta Integritas di KPU Kabupaten Minahasa
}

\author{
Firti H Mamonto ${ }^{\text {a, }}{ }^{*}$, Jeane Elisabeth Langkai ${ }^{\text {b, } 2}$, Rebecca C. Mowilos ${ }^{\text {c, } 3}$ \\ ${ }^{a}$ Universitas Negeri Manado, Ilmu Administrasi Negara, Tondano, Indonesia \\ ${ }^{1}$ friscakuhu16@gmail.com *; jeanelangkai59@gmail.com; rebeccamowilos25@gmail.com
}

\section{INFO ARTIKEL}

Diterima 00 April 00

Disetujui 00 Oktober 00

Key word:

Implementation of the Integrity Pact Policy KPU Minahasa Regency

\section{A B S T R A C T}

This study aims to describe the implementation of the integrity pact policy in the KPU of Minahasa Regency. This study uses a qualitative approach, with data collection techniques, namely: observation, documentation, and interviews. Data sources are: KPU members and staff along with PPK, PPS and KPPS. Data were analyzed descriptively qualitatively. The results showed that:, 1). The low commitment of KPU, PPK, PPS and KPPS in implementing the integrity pact 2). Policies have not been socialized or communicated appropriately, correctly and thoroughly to many implementers and communities, 3). There were technical difficulties in implementing the integrity pact, 4). The socio-cultural conditions of the community that have not supported the implementation of the integrity pact, 5). Attitudes and behavior of implementers that do not yet support the implementation of the integrity pact, it is suggested that: 1). KPU, PPK, PPS and KPPS are committed to implementing the integrity pact 2). Policies are socialized or communicated appropriately, correctly and thoroughly to implementers and society, 3). Technical difficulties in implementing the integrity pact need to be anticipated before implementation, 4) Create social and cultural conditions that support the implementation of the integrity pact, 5). Attitudes and behavior of implementers support the implementation of the integrity pact..

\section{INTISARI}

Penelitian ini bertujuan untuk mendeskripsi implementasi kebijakan pakta integritas di KPU Kabupaten Minahasa. Penelitian ini menggunakan pendekatan kualitatif, dengan teknik pengumpulan data yaitu: observasi, dokumentasi, dan wawancara. Sumber data adalah: Anggotaa KPU dan staf beserta dengan PPK, PPS dan KPPS. Data dianalisis secara deskriptif kualitatif. Hasil penelitian menunjukkan bahwa: , 1). Rendahnya komitmen KPU, PPK, PPS dan KPPS dalam mengimlementasikan pakta integritas 2). Kebijakan belum disosialisasikan atau dikomunikasikan secara tepat, benar dan menyeluruh kepada banyak implementer dan masyarakat, 3). Terjadi kesulitan teknis dalam mengimplementasikan pakta integritas, 4). Kondisi social budaya masyarakat yang belum mendukung implementasi pakta integritas, 5). Sikap dan perilaku implementer yang belummendukung implementasi pakta integritas, Untuk itu disarankan sebaiknya: 1). KPU, PPK, PPS dan KPPS berkomitmen untuk mengimlementasikan pakta integritas 2). Kebijakan disosialisasikan atau dikomunikasikan secara tepat, benar dan menyeluruh kepada implementer dan masyarakat, 3). Kesulitan teknis dalam mengimplementasikan pakta integritas perlu diantisipasi sebelum implementasi, 4).Diciptakan kondisi social budaya masyarakat yang mendukung implementasi pakta integritas, 5). Sikap dan perilaku implementer mendukung implementasi pakta integritas.

\footnotetext{
* Korespondensi Penulis ; e-mail: friscakuhu16@gmail.com
} 
Copyright (C) 2019 (Fitri Mamonto). All Right Reserved

\section{Pendahuluan}

Hubungan Lintas antara penduduk perbatasan Indonesia (kabupaten Kepulauan Sangihe dan kabupaten kepulauan Talaud) dan Philipina Selatan telah berjalan puluhan tahun. Hubungan ini terkonsentrasi pada dua wilayah, di kabupaten Kepulauan Talaud konsentrasi hubungan terfokus di pulau Miangas dan desa Bowombaru pulau Kabaruan. Sementara khusus di kabupaten Sangihe, hubungan lintas batas antara dua penduduk dari dua wilayah terfokus di kecamatan Marore, dan sebagian (secara sembunyi- sembunyi) di Desa Peta. Adapun penduduk Philipina Selatan adalah yang berasal dari wilayah-wilayah Davao, Balut Island, Cape San Agustin, Sarangani Island, dan daerah kepulauan Tawi-Tawi. Kesepakatan pengaturan lintas batas antar dua negara ditandatangi di Jakarta pada tahun 1975 dengan nama JOINT IMPLEMENTATION OF THE BORDER PATROL AGREEMENT AND BORDER CROSSING AGREEMENT BETWEEN THE GOVERNMENT OF THE REPUBLIC OF INDONESIA AND THE GOVERNMENT OF THE REPUBLIC OF THE PHILIPPINES.

Border Crossing Agreement yang di dalamnya mengatur 3 hal yaitu :

1. Visit of Relatives (kunjungan kekeluargaan).

2. Religoius trip (kunjungan keagamaan).

3. Pleasure.

Kenyataannya, hubungan lintas batas antar penduduk yang di wilayah tersebut sudah jauh "keluar" dari hal-hal yang diatur di dalam Border Crossing Agreement. Persoalannya adalah hal ini berdampak secara signifikan terhadap perekonomian wilayah perbatasan. Hasil dari penelitianpenelitian sebelumnyaIa[1],

memperlihatkan bahwa hubungan lintas batas sudah menjadi hubungan perdagangan lintas batas. Adapun hal-hal yang teridentifikasi adalah sebagai berikut :

1. Penduduk Philipina Selatan banyak membawa berbagai barang dan dijual di wilayah Indonesia (konsentrasi di pulau Marore).

2. Joint illegal fishing antara penduduk dua wilayah.

3. Masuknya minuman keras dari Philipine secara ilegal di Marore, Peta dan Tahuna.

Kondisi ini memperlihatkan bahwa perlu dilakukan update terhadap Border Crossing Agreement antara dua negara. Atas dasar ini maka perlu dilakukan penelitian lebih mendalam untuk mendapatkan data-data yang lebih mendalam terkait dengan ini hal ini.

Oleh karenanya, maka atas dasar persoalan di atas maka penelitian berupaya untuk menjawab pertanyaan (rumusan masalah) sebagai berikut : "bagaimanakah seharusnya pengaturan hubungan lintas batas antara penduduk perbatasan Indonesia dan Philipina di dalam Border Crossing Agreement antara dua negara ?".

Selanjutnya penelitian ini bertujuan untuk menghasilkan rekomendasi kebijakan yang akan disampaikan kepada lembaga terkait (Kementerian Luar Negeri RI, Kementerian Pertahanan Keamanan RI, Kementerian Kelautan dan Perikanan RI. Kementerian Hukum dan HAM RI), tentang rumusan baru yang tepat untuk dimuat dalam Border Crossing Agreement antara Indonesia dan Philipina. Adapun manfaat yang diharapkan dapat diperoleh dari penelitian ini adalah dapat memberikan penguatan terhadap perkembangan konseo dan teori-teori kebijakan, terutama sekali terkait dengan formulasi kebijakan, serta dapat menjadi rujukan bagi perbaikan dan penguatan content dari Border Crossing Agreement antara Indonesia dengan Philipina.

\section{Metode Penelitian}

Desain dari penelitian ini adalah kualitatif. Tujuannya adalah untuk menggambarkan, meringkaskan berbagai kondisi, berbagai situasi, atau berbagai fenomena realitas sosial yang ada, kemudian berupaya untuk menarik realitas ke permukaan sebagai suatu ciri, kharakter, sifat, model, tanda, atau gambaran tentang kondisi, ataupun fenomena tertentu. Format ini fokus pada suatu unit tertentu dari berbagai fenomena. Adapun data yang dipergunakan dalam penelitian ini adalah data primer dan data sekunder. Data primer adalah data yang langsung direkam di lapangan melalui wawancara mendalam dan yang didapat melalui observasi yang dilakukan oleh peneliti sendiri. Sementara itu data sekunder adalah data olahan atau data telah dipublikasikan secara resmi yang didapat dari berita media, dokumentasi dan arsip lembaga terkait lainnya. sementara informan dalam penelitian ini adalah Pedagang lintas batas dari pihak Indonesia (3 orang), Pedagang lintas batas dari pihak Philipina (3 orang). Camat di Desa-desa perbatasan. Masyarakat di sekitar area perdagangan lintas batas (3 orang). Kepala Bidang Pengelolaan Perbatasan Pemerintah provinsi Sulawesi Utara, dan Asisten I pemerintah Kabupaten Kepulauan Talaud.

Penelitian ini menggunakan teknik pengumpulan data wawancara mendalam (in depthinterview). Pada dasarnya wawancara mendalam yang dilakukan dalam penelitian ini merupakan wawancara tidak berstruktur, meskipun disiapkan pula pedoman untuk melakukan wawancara. Kegiatan wawancara dengan para informan dilakukan di tempat yang berbeda-beda, sesuai dengan kesepakatan y yang dibuat. Peneliti mendatangi satu per satu para informan di tempat yang berbeda-beda. Selanjutnya Teknik pengujian keabsahan data yang dilakukan dalam penelitian ini adalah menggunakan teknik triangulasi. Data dan 
temuan-temuan baru yang diperoleh, diuji dengan melakukan cross check data, kemudian dianalisa dengan cara mengkombinasikan interpretasi peneliti dengan teori rujukan, serta teori lainnya yang berkaitan dengan temuan-temuan dalam penelitian.

\section{Hasil dan Pembahasan}

$\begin{array}{rccr}\text { Penelitian } & \text { lapangan } & \text { dilakukan } & \text { di } \\ \text { kantor Kabupaten } & \text { Kepulauan } & \text { Talaud, desa }\end{array}$ Makatara Kecamatan Beo Utara, Desa Bulude kecamatan Essang dan Desa Bowombaru kecamatan Melonguane Timur. Penelitian di kantor Bupati adalah menggali data dari pejabat Asisten I yang salah satu bidang yang menjadi tanggung jawabnya adalah soal pelintas batas. Tiga desa di kabupaten Kepulauan Talaud ini adalah desa-desa yang terdapat kelompok atau keluarga-keluarga yang merupakan pelintas batas. ada tiga kharakteristik pelintas batas yang ditemukan yaitu:

1. Pertama adalah pelintas batas warga negara Indonesia (penduduk kepulauan Talaud dan atau Sangihe) yang melakukan kegiatan lintas batas, murni untuk tujuan perdagangan. Perdagangan yang umum dilakukan adalah bidang perikanan,dan kemudian adalah bahan-bahan kebutuhan primer seperti sabun cuci, sabun mandi, dan rokok sebagai produk Indonesia yang paling disukai oleh masyarakat Philipina Selatan. Hasil tangkapan ikan dari wilayah laut Kepulauan Talaud dibeli dengan harga tinggi dan mendapatkan perlakuan yang jauh lebih baik dibandingkan jika dijual di pelabuhan pelelangan ikan kota Bitung (hasil wawancara dengan komunitas pelintas batas di desa Makatara, dan desa Bulude).

2. Kedua adalah pelintas batas orang kepulauan Talaud dan dari kepulauan Sangihe yang memiliki hubungan kekerabatan yang erat dengan saudarasaudara mereka yang sebagian besar sudah lahir dan menetap di philipina Selatan. Tujuan utama dari perjalanan lintasnya adalah untuk kunjungan kekeluargaan sekaligus juga untuk berdagang. Umumnya berangkat dengan membawa hasil tangkapan ikan, kem

3. Kategori ke tiga adalah warga Philipina Selatan, etnik asli phillipina Selatan yang masuk ke wilayah kabupaten kepulauan Talaud untuk tujuan perdagangan.

4. Kategori ke empat adalah etnik Sangihe dan etnik Talaud yang lahir atau sudah bertahun-tahun tinggal di Philipina Selatan dan sudah menjadi warga negara, yang melakukan pelayaran lintas batas untuk tujuanp erdagangan dan kunjungan kekeluargaan.

5. Kategori ke lima adalah etnik Sangihe dan etnik Talaud yang lahir atau sudah bertahun-tahun tinggal di Philipina Selatan, tetapi memilih untuk tidak menjadi warga negara Phillipina. Tujuan perjalanan lintas batasnya adalah untuk kunjungan kekeluargaan dan sedikit untuk tujuan perdagangan.
Dari hasil wawancara yang dilakukan diperoleh data bahwa, pada dasarnya hubungan lintas batas ini dapat memberikan keuntungan yang signifikan bagi warga perbatasan. Namun demikian hal tidak tercapai oleh karena terkendala tidak adanya regulasi maupun perjanjian perbatasan antara Indonesia dan Philipina. Ikan dari perairan kepulauan Talaud merupakan komoditas dengan harga jual tinggi di Philipina Selatan, sementara rokok Indonesia sangat disukai oleh masyarakat Phillipina Selatan. dari hasil penjualan ikan di Phillipina Selatan, orang-orang perbatasan membeli barang-barang sekunder seperti berbagai keperluan rumah tangga. Di desa Makatara misalnya, ditemukan material untuk pembuatan perahu yang merupakan produk Phillipina. Ini dibeli oleh komunitas pelintas batas, kemudian dibawa ke wilayah Talaud.

Namun demikian persoalannya adalah perdagangan seperti ini, menjadi sebuah perdagangan yang sifatnya ilegal dan tidak memberikan keuntungan bagi daerah. Dari penelitian ini juga ditemukan bahwa sentra perdagangan ilegal dalam jumlah yang besar adalah berada di Pulau Marore yang masuk dalam wilayah kabupaten kepulauan Sangihe. Dari sini kemudian barang-barang yang masuk terdistribusi secara ilegal ke ibukota kabupaten Kepulauan Sangihe (Tahuna) dan kabupaten Kepulauan Talaud (Melonguane). Di dua pusat kota ini barang-barang Phillipine ada yang jual secara terang-terangan dan ada yang dijual secara sembunyi-sembunyi.

Pada dasarnya kondisi ini memperlihatkan bahwa perjanjian perbatasan antara Indonesia -

P. hillipine yang berbunyi seba.gai Border Crossing Agreement, sudah sangat urgen untuk segera direvisi. Oleh karena ternyata hubungan lintas batas antara masyarakat dua negara ini, sangat berpotensi untuk mengembangkan perekonomian masyarakat wilayah perbatasan.

\section{Kesimpulan}

Dari hasil penelitian yang telah selesai dilakukan maka diperoleh kesimpulan sebagai berikut :

1. Border Crossing Agreement antara Indonesia Phillipina sudah tidak relevan dan tidak dapat mengakomodir berbagai "bentuk" kegiatan pelintas batas antara masyarakat dua negara.

2. Kegiatan lintas batas antar dua negara, berpotensi untuk memberikan keuntungan ekonomi yang signifikan bagi masyarakat perbatasan di wilayah kabupaten Kepulauan Talaud dan juga termasuk kabupaten kepulauan Sangihe.

3. Border Crossing Agreement belum juga direvisi oleh karena kurangnya perhatian pemerintah antar dua negara, terutama sekali dari pihak Indonesia.

4. Keamanan. Karena Patroli perbatasan menjadi "masalah" tersendiri bagi para nelayan dan pelintas batas.

5. Revisi Border Crossing Agreement harus segera dilakukan, dan diikuti dengan pengaturan- 
pengaturan yang sifatnya lebih teknis.

\section{Referensi}

[1] M. Mamentu and R. Joyce, Evaluasi Dampak Sosial Ekonomi Dan Politik Border Crossing Agreement Pada Masyarakat Perbatasan Kabupaten Kepulauan Talaud Provinsi Sulawesi Utara (Studi Dalam Rangka Rekomendasi Revisi Kebijakan Pengaturan P. Manado: Jurnal LPPM Unsrat, 2017.

[2] Islamy, M. Irfan, Prinsip-Prinsip Perumusan Kebijakan Negara., Jakarta : Bumi Aksara, 2002

[3] Pengembangan Program Pemberdayaan Nelayan Tangkap Di Kabupaten Kepulauan Talaud., Manado :

Jurnal LPPM Unsrat, 2016

[4] Mamuaja, Bertha., Pelaksanaan Kebijakan Border Crossing Agreement oleh Kantor Imigrasi Kabupaten Kepulauan Sangihe (penelitian)., Manado : FISIP Unsrat, 2017

[5] Nugroho, D. Riant, Kebijakan Publik Untuk Negara- Negara Berkembang. PT Alex Media Komputindo:

Jakarta, 2008

[6] Winarno Budi., Kebijakan Publik Era Globalisasi., Yogyakarta : CAPS, 2016 